\title{
Relation between Blood Group Type and Fully Impacted Teeth
}

\author{
Authors \\ Dr Mohammed Ahmad Assiri, Dr Mohammed Ahmed Al Masoudi, \\ Dr Saad Awadh Al Obaid, Dr Mohammed Awadh Al Obaid, Dr Hossam A. Eid
}

\section{Introduction}

The blood group distribution also shows variety according to races. It was reported that the group A has a wider distribution in Eskimos, the group B in Chinese and Indians, the group $\mathrm{O}$, on the other hand, in American Canadian Indians and Czechoslovakians and those living in Kenya. ${ }^{(5)}$ According to statistical distribution of the ABO blood types in the Turkey, $42.5 \%$ had type $\mathrm{A}$ and $33.7 \%$ had type $\mathrm{O}$ and $15.8 \%$ had type $B$, and $8.0 \%$ had type $A B$ blood (5). When the rate of $\mathrm{Rh}+$ is considered, it was reported to be about $85 \%$ in all the population. However, varying percentages were reported in various countries of the world (Kenya 96\%, India $99 \%$, Iran $90 \%$, Turkey $87 \%)$. ${ }^{(5,6)}$

ABO blood groups are the most investigated erythrocyte antigen system, and owing to ease of identifying their phenotypes, they have been used as genetic markers in studies of their associations with various diseases ${ }^{(7,8)}$. Studies from the 1950s demonstrated that blood group $\mathrm{O}$ is associated with duodenal ulcer disease, while gastric ulcer and gastric carcinoma are associated with blood group A. ${ }^{(9)}$

Although several studies have been carried out to investigate relationships between the $\mathrm{ABO}$ blood groups and the incidence of certain diseases in medicine, little investigation has been made to explore the relationships between $\mathrm{ABO}$ blood groups and the incidence of oral and dental diseases.

\section{Aim of study}

Was to investigate the correlation between blood group type and incidence of tooth impaction among outpatient, college of Dentistry, KKU, KSA.

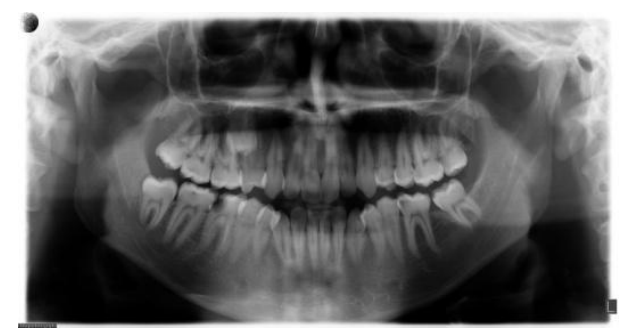

Fig 1 showing upper right 2nd premolar impaction.

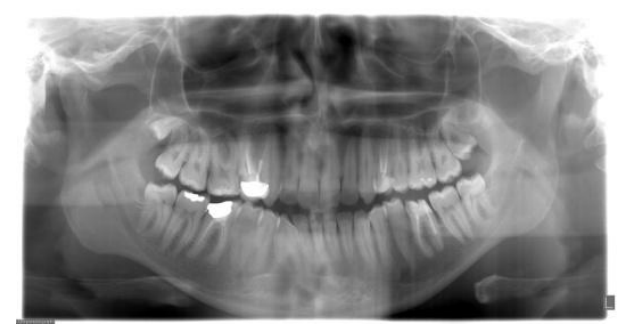

Fig 2 showing upper right \& left molars impaction.

\section{Methodology}

This study was carried out on adult dental outpatients who attended the Oral Diagnostic Clinic at the College of Dentistry, King Khalid University, Abha, Saudi Arabia, for an oral examination and a 


\section{JMSCR Vol||05||Issue||01||Page 15841-15844||January}

dental treatment plan. The study sample included adult subjects who were older than 26.83 years of age. The college is an open public facility and referral hospital. A total of 178 patients were interviewed and clinically investigated for the presence of oral lesions from October 2012- to December 2012. History taking and a thorough oral clinical examination including panoramic $\mathrm{x}$-ray was performed, As well as taking the individual blood group type via an official letter from medical department confirmed blood group type and distribution of tooth impaction among different blood group types was recorded.

A statistical analysis was carried out using SPSS software for Windows v.16 (SPSS Inc., Chicago, IL, USA). First, mean values with standard deviation were calculated. Crosstabulation and Chi-square test were used to analyze the effect of gender on halitosis.

\section{Results}

\section{GENDER}

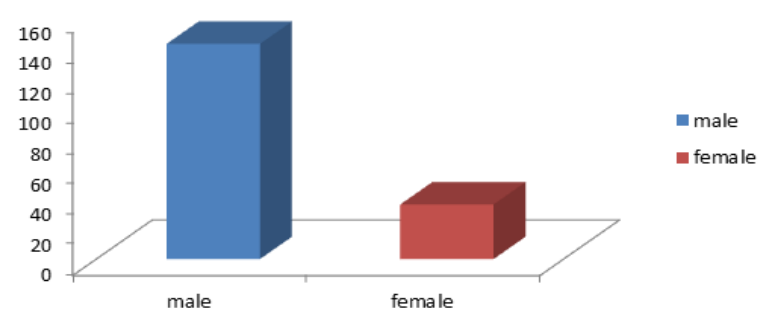

Graph 1: Distribution of subjects according Gender As shown in graph 1, majority of the subjects who underwent impactions were males ie, $79.8 \%$.

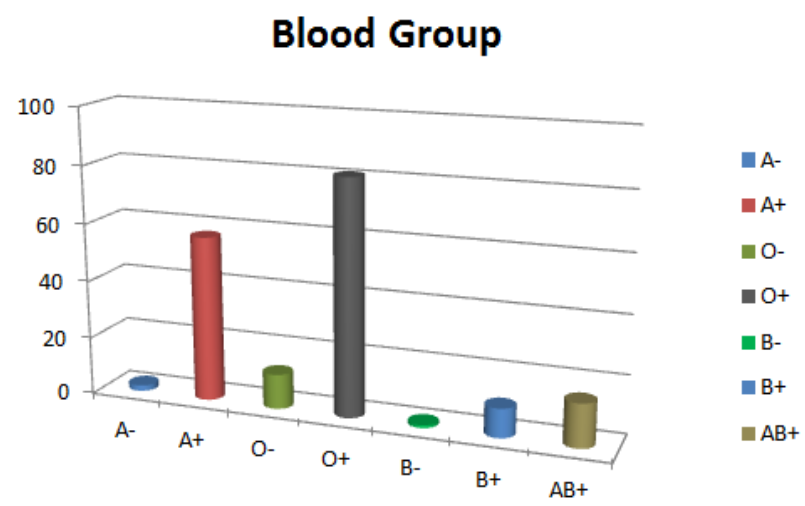

Graph 2: Distribution of subjects according Blood group
As shown in graph 2 the subjects with blood group $\mathrm{O}+$ and $\mathrm{A}+$ were highest, i.e. $45.5 \%$ \& $32 \%$ respectively. \& the blood group B- \& A- were lowest i.e. $0.6 \%$ \& $1.1 \%$ respectively.

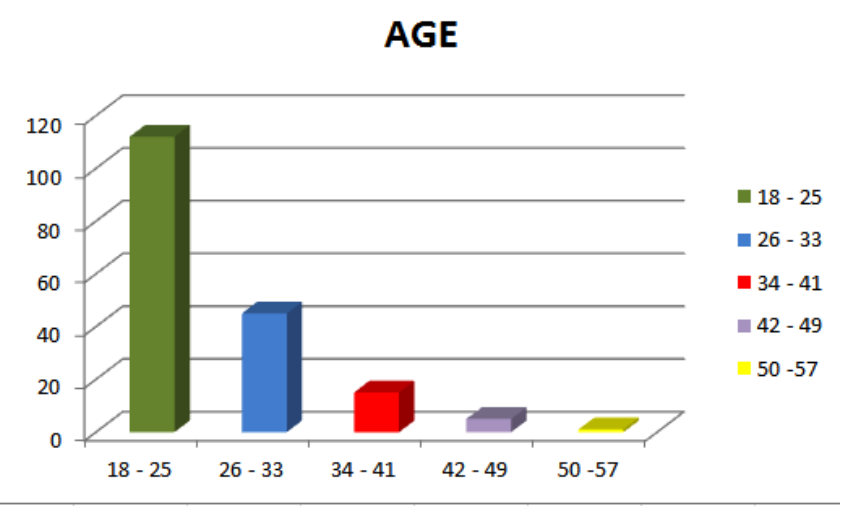

Graph 3: Distribution of subjects according the Age

As shown in graph 3 it can be seen that majority of the subjects were belonging to the age group 18-25 years $(62.9 \%)$, and gradually lesser subjects as the age increases. Lower number of the subjects were seen in the age group of 50-57 years $(0.6 \%)$.

The study was done at dental clinic, College of Dentistry at King Khalid University. We find the majority of the subjects who underwent impactions were males i.e. $79.8 \%$. It also appears the subjects with blood group $\mathrm{O}+$ and $\mathrm{A}+$ were highest, i.e. $45.5 \%$ $\& 32 \%$ respectively \& the blood group B- \& Awere lowest i.e. $0.6 \% \& 1.1 \%$ respectively. Also, we can see the majority of the subjects were belonging to the age group 18-25 years (62.9\%), and gradually lesser subjects as the age increases. Lower number of the subjects were seen in the age group of 50-57 years $(0.6 \%)$.

Data suggested that a positive correlation between blood group type $\mathrm{O}+$ and tooth impaction compare to other groups, as well as, the incidence of impaction in males more than females specially in younger age group as shown in the diagram. 


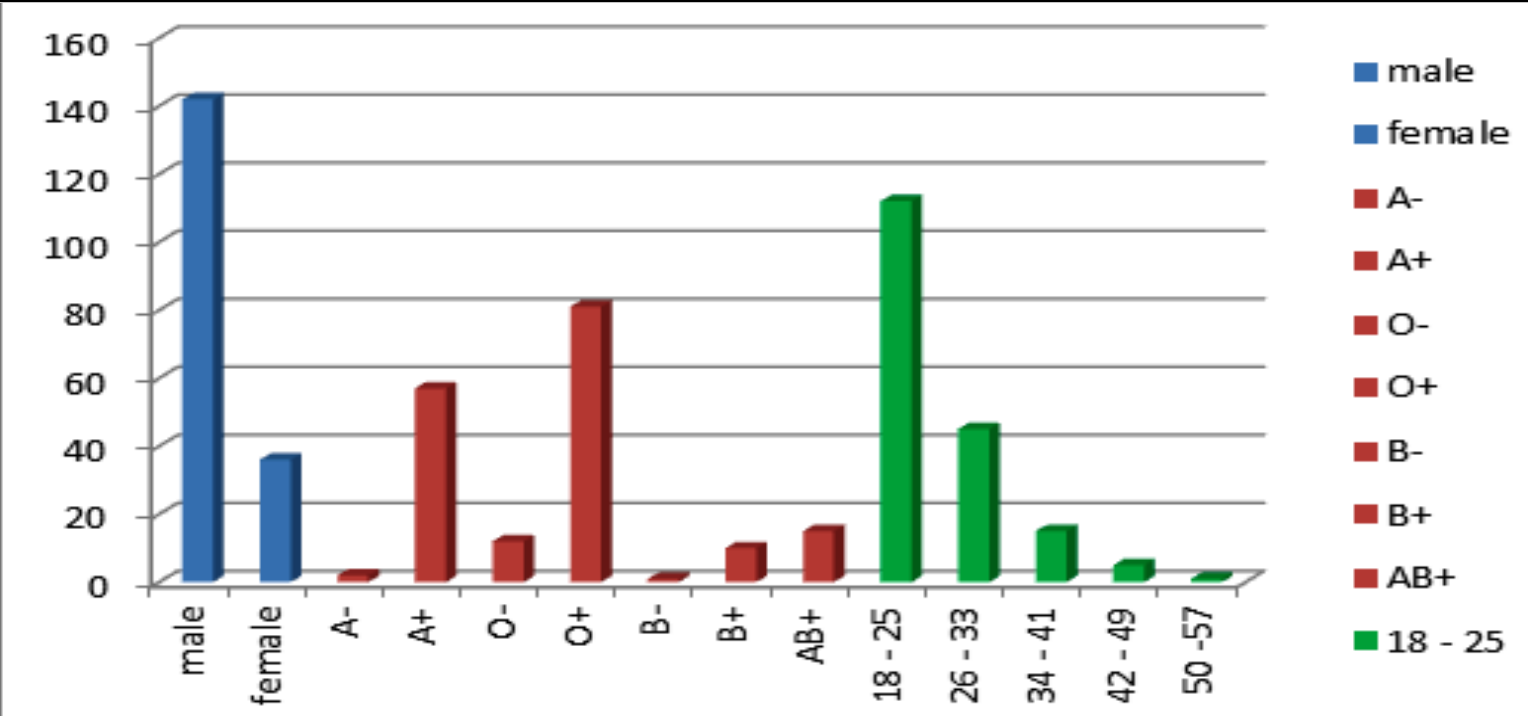

\section{Discussion}

Some authors ${ }^{(15,16)}$ claimed that, ABO blood types constituted an increased risk for the development of oral diseases whereas a small group of researchers failed to find this increased risk. It is known that $\mathrm{ABO}$ blood types indicate differences in terms of their proportion according to races ${ }^{(17)}$. It is also known that periodontal diseases show proportional differences in distribution among races. When this point is taken into consideration, the question arises whether or not the proportion of $\mathrm{ABO}$ blood subgroup distribution is effective on the proportion of distribution of periodontal disease in various societies. However, little investigations have been made to explore the $\mathrm{ABO}$ blood groups and the incidence of oral and dental diseases. In the earliest investigation on this matter, Suk suggested that particular blood groups and a tendency towards caries might be constitutional characters and they were not particularly related to race, though the $\mathrm{O}$ group and good teeth were less common in civilized people than in primitive races ${ }^{(18)}$.

Suk's investigation was followed by a study carried out by Aitchison and Carmichael, which revealed a relationship between the patient's susceptibility to caries and his blood group ${ }^{(11)}$ The present study researched the relationship between $\mathrm{ABO}$ blood subgroups and periodontal diseases in the light of the above data. In this study, it was determined that there was a relatively higher percentage of A blood group in patients with gingivitis, Gawrzewska ${ }^{(15)}$ found individuals of blood group $\mathrm{O}$ to have greater severity of periodontal diseases, but individuals of blood group A to have greater resistance to periodontal diseases. Suk found that ABO blood types had an increased effect on the risk for the development of oral diseases. Pradhan et al ${ }^{(16)}$ also found significant differences when $\mathrm{ABO}$ blood groups were related to four grades of periodontal involvement. In one early investigation, O'Rark and Lyschon (19) found a statistical significance regarding the relation between M.N. blood groups and caries history. On the contrary, Barros and Witkop ${ }^{(12)}$ stated that there were no significant differences between subjects with or without periodontal diseases regarding $\mathrm{ABO}$ blood group. .

\section{Conclusion}

Long-term epidemiological studies are needed to make more comprehensive assessment of the effects of $\mathrm{ABO}$ group on oral diseases.

\section{References}

1. Altenburg A, Micheli CK, Maldini C, Mahr A, Puttkammer M, Zouboulis CC. Clinical aspects and treatment of recurrent aphthous ulcers. Hautarzt. 2012 Sep;63(9):693-703.

2. Scully C, Porter S. Oral mucosal disease: Recurrent aphthous stomatitis. Br J Oral Maxillofac Surg. 2008;46:198-206.

3. Stanley HR. Aphthous lesions. Oral Surg Oral Med Oral Pathol Oral Radiol Endod. 1972;30:407-16. 
4. Wray D, Graykowski EA, Notkins AL. Role of mucosal injury in initiating recurrent aphthous stomatitis. Br Med J (Clin Res Ed) 1981;283:1569-70.

5. Bookman R. Relief of Canker Sores on Resumption of Cigarette Smoking. Calif Med. 1960;93:235-6.

6. Grady D, Ernster VL, Stillman L, Greenspan J. Smokeless tobacco use prevents aphthous stomatitis. Oral Surg Oral Med Oral Pathol. 1992;74:463-65.

7. Natah SS, Konttinen YT, Enattah NS, Ashammakhi N, Sharkey KA, HäyrinenImmonen R. Recurrent aphthous ulcers today: A review of growing knowledge. Int $\mathbf{J}$ Oral Maxillofac Surg. 2004;33:221-34.

8. Gallo Cde B, Mimura MA, Sugaya NN. Pschological stress and recurrent aphthous stomatitis. Clinics (Sao Paulo) 2009;64:6458.

9. McCartan BE, Sullivan A. The association of menstrual cycle, pregnancy and menopause with recurrent oral aphthous stomatitis: A review and critique. Obstet Gynecol. 1992;80:455-8.

10. Hoover CI, Olson JA, Greenspan JS. Humoral responses and cross reactivity to viridians streptococci in recurrent aphthous ulceration. J Dent Res. 1986;65:1101-4.

11. Leimola-Virtanen R, Happonen RP, Syrjänen S. Cytomegalovirus (CMV) and Helicobacter pyroli (HP) found in oral mucosal ulcers. J Oral Pathol Med. 1995;24:14-7.

12. Porter SR, Barker GR, Scully C, Macfarlane G, Bain L. Serum IgG antibodies to Helicobacter pyroli in patients with recurrent aphthous stomatitis and other oral disorders. Oral Surg Oral Med Oral Pathol Oral Radiol Endod. 1997;83:325-8.

13. Hooks JJ. Possibility of a viral etiology in recurrent aphthous ulcers and Behcet's syndrome. J Oral Pathol. 1978;7:353-64.

14. Sun A, Chang JG, Kao CL, Liu BY, Wang JT, Chu CT, et al. Human cytomegalovirus as a potential etiologic agent in recurrent aphthous ulcers and Behcet, $\mathrm{s}$ disease. J Oral Pathol Med. 1996;25:212-8.

15. Sun A, Chang JG, Chu CT, Liu BY, Yuan $\mathrm{JH}$, Chiang CP. Preliminary evidence for an association of Epstein - Barr virus with preulcerative oral lesions in patients with recurrent aphthous ulcers or Behcet's disease. J Oral Pathol Med. 1998;27:168-75.

16. Jacobson JM, Greenspan JS, Spritzler J, Ketter N, Fahey JL, Jackson JB, et al. Thalidomide for the treatment of oral aphthous ulcers in patients with human immunodeficiency virus infection. National Institute of Allergy and Infectious Diseases AIDS Clinical Trials Group. N Engl J Med. 1997;336:1487-93. [

17. Zabel P, Schade FU, Schlaak M. Inhibition of endogeneous TNF- $\alpha$ formation by pentoxifylline. Immunobiology. 1993;187:447-63.

18. Natah SS, Konttinen YT, Enattah NS, Ashammakhi N, Sharkey KA, Häyrinen-Immonen R. Recurrent aphthous ulcers today: A review of growing knowledge. Int $\mathrm{J}$ Oral Maxillofac Surg 2004;33:221-34.

19. Wray D, Ferguson MM, Hutcheon WA, Dagg JH. Nutritional deficiencies in recurrent aphthae. J Oral Pathol 1978; 7: 418-23.

20. Porter SR, Scully C, Flint S. Hematologic status in recurrent aphthous stomatitis compared with other oraldisease. Oral Surg Oral Med Oral Pathol 1988; 66: 41-4.

21. B. Praveen Kumar, MDS1/Vaishali Keluskar, MDS2/ Anjana S. Bagewadi, MDS3/Arvind Shetti, MDS3 Evaluating and comparing phagocytic functions of salivary and blood neutrophils in patients with recurrent aphthous ulcers and controls. Quintessence International. Vol 41 • N 5 • May 2010. 